L. Delgado-Plasencia ${ }^{a, *}$, N. Hernández-Siverio ${ }^{b}$

y D. Castro-Díaz

${ }^{a}$ Servicio Cirugía General y Digestiva, Hospital Universitario de Canarias, Canarias, España

bServicio de Urología y Urología Pediátrica, Hospital Universitario

de Canarias, Canarias, España
*Autor para correspondencia.

Correos electrónicos: lucianodelgado1@gmail.com, luciano_delgado1@yahoo.es (L. Delgado-Plasencia).

\title{
Metrorragias como forma de presentación de un carcinoma de células renales con metástasis ovárica
}

\section{Methroragies as form of presentation of a ovary metastases from a primary renal cell carcinoma}

\section{Sr. Director:}

Presentamos el caso de una mujer de 52 años que consultó por episodios repetidos de metrorragias así como síndrome general consistente en astenia y anorexia. A la exploración no llamaba nada la atención tan solo restos hemorrágicos en la exploración vaginal. Una ecografía vaginal evidenció la presencia de una masa sólido quística dependiente del anejo izquierdo, confirmándose posteriormente por TC (fig. 1), con pequeña cantidad de líquido libre intraperitoneal. Así mismo, el TC evidenció la presencia de una masa sólida de $6,5 \times 6,5 \mathrm{~cm}$ dependiente del polo inferior del riñón derecho (fig. 2), así como múltiples nódulos en polo superior. Se practicó nefrectomía radical derecha así como histerectomía y ooforectomía bilateral siendo informada la pieza renal como carcinoma de células claras Furhman III, sin invasión de la

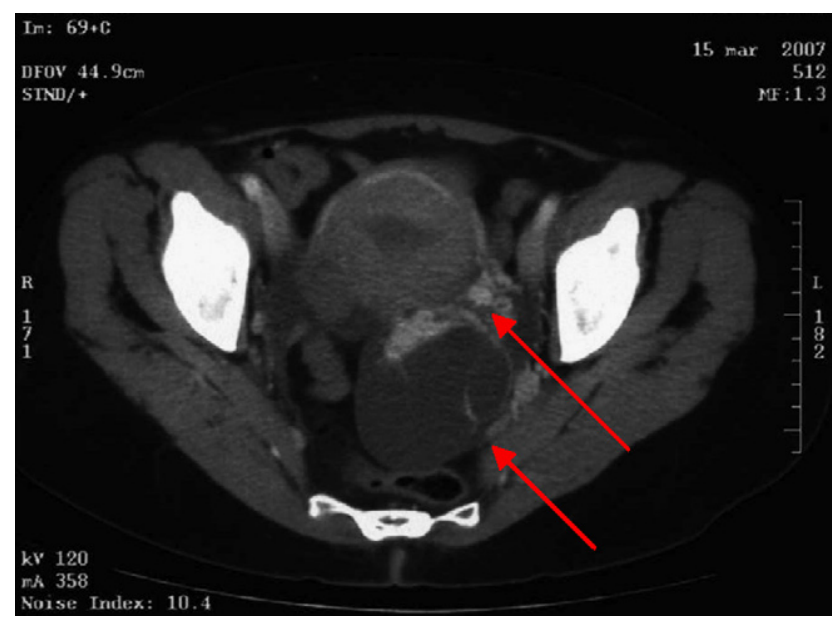

Figura 1 - TC. Componente sólido quístico de la masa anexial (flecha).

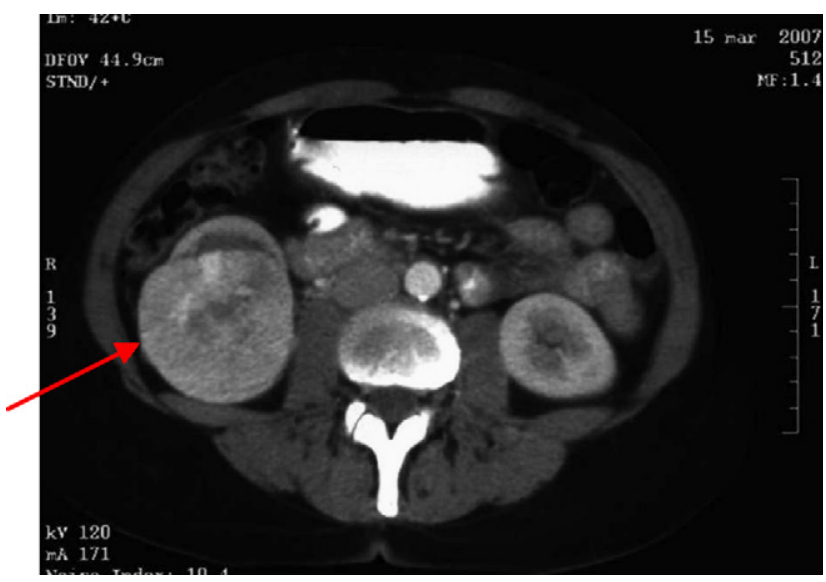

Figura 2 - TC. Masa compleja de $65 \times 65 \mathrm{~mm}$ dependiente del polo inferior del riñón derecho (flecha).

cápsula renal, mientras que el ovario derecho presentaba metástasis de carcinoma renal de células claras.

La metástasis ovárica de la adenocarcinoma renal de la célula es absolutamente rara. Se confunden a menudo con tumores claros primarios de la célula del ovario. Aproximadamente un tercio de los pacientes con nuevo diagnóstico de carcinoma renal presentarán enfermedad metastásica de inicio $^{1}$. Por otro lado, cerca de la mitad de los pacientes que son nefrectomizados con intención curativa, sufrirán metástasis a distancia durante el seguimiento ${ }^{2,3}$. El 70\% de las metástasis están limitadas a un solo órgano, generalmente pulmón (40\%) o hueso (22\%), siendo únicas en el 2,3\% de los casos $^{4}$. Con tan solo 12 casos publicados en los últimos 20 años, la afectación metastásica del ovario con primario de origen renal es extremadamente rara, pero la afectación metastática de un carcinoma renal debe ser incluida en el diagnóstico diferencial de los tumores de ovario con histología de célula clara 5 . 
B I B L I O G R A F Í A

1. Toyoda Y, Shinohara N, Harabayashi T. Survival and prognostic classification of patients with metastatic renal cell carcinoma of bone. Eur Urol. 2007;52:163-9.

2. Sheth S, Scatarige JC, Horton KM. Current concepts in the diagnosis and management of renal cell carcinoma: role of multidetector CT and three-dimensional CT. Radiographics. 2001;21:237-41.

3. Zisman A, Pantuck AJ, Dorey F. Improved prognostication of renal cell carcinoma using integrated staging system. J Clin Oncol. 2001;19:1649-55.

4. Whelan P. The medical treatment of metastatic renal cell carcinoma. EUA Update Series. 2003;1:237-44.

5. Shinojima T, Nakajima Y, Kiguchi H. Renal cell carcinoma metastatic to the ovary: a case report. Nippon Hinyokika Gak Zass. 2001;92:694-7.
M. Álvarez-Múgica ${ }^{\mathrm{a}, *}$, V. Bulnes Vázquez ${ }^{\mathrm{b}}$, A. Jalón Monzón ${ }^{\mathrm{c}}$ y F.J. Regadera Sejas ${ }^{c}$

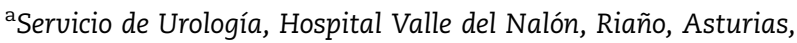
España

bervicio de Radiodiagnóstico, Hospital Álvarez-Buylla, Mieres, Asturias, España

'Servicio de Urología, Hospital Universitario Central de Asturias, Oviedo, España

*Autor para correspondencia.

Correo electrónico: malvarezmug@gmail.com

(M. Álvarez-Múgica).

\section{Tumor filoide de la vesícula seminal: caso clínico y revisión de la literatura}

\section{Phyllodes tumour of the seminal vesicle: case report and revision of literature}

\section{Sr. Director:}

Le presentamos el caso de un hombre con 64 años, asintomático, con masa supraprostática diagnosticada en ultrasonido transrectal. El nivel sérico del antígeno específico de la próstata (PSA) fue $0,53 \mu \mathrm{g} / \mathrm{l}$. La resonancia magnética (RMN) pélvica mostró una formación de bordes regulares, de predominio quístico, con una vegetación interna sólida, en la topografía de la vesícula seminal izquierda, no presentando ninguna señal de agresividad local o regional (fig. 1).
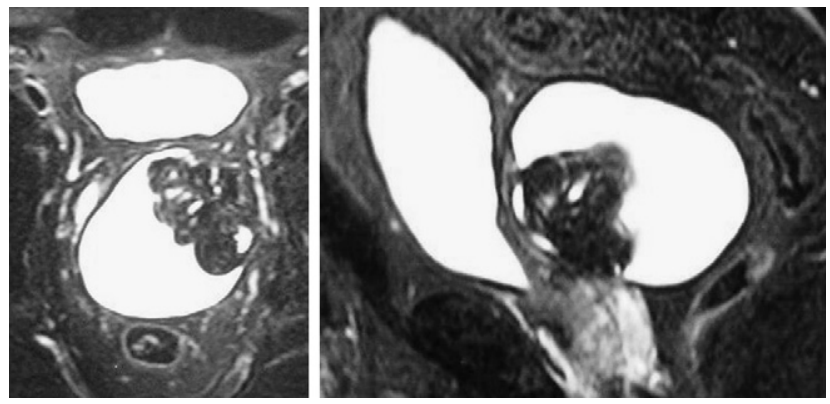

Figura 1 - RMN axial y sagital: formación en la topografía de la vesícula seminal izquierda, de bordes regulares, de predominio quístico, con una vegetación sólida de $5 \mathrm{~cm}$ en su interior.
Por laparotomía media infraumbilical y por corte de la bolsa de Douglas, se hizo la exéresis completa de la masa (fig. 2), adherente a la próstata, no siendo posible identificar la vesícula seminal izquierda. El periodo posquirúrgico transcurrió sin problemas.

El examen patológico mostró una formación quística con un nódulo sólido papilar. Al corte era compacta y elástica, observándose tejido prostático y de la vesícula seminal en su

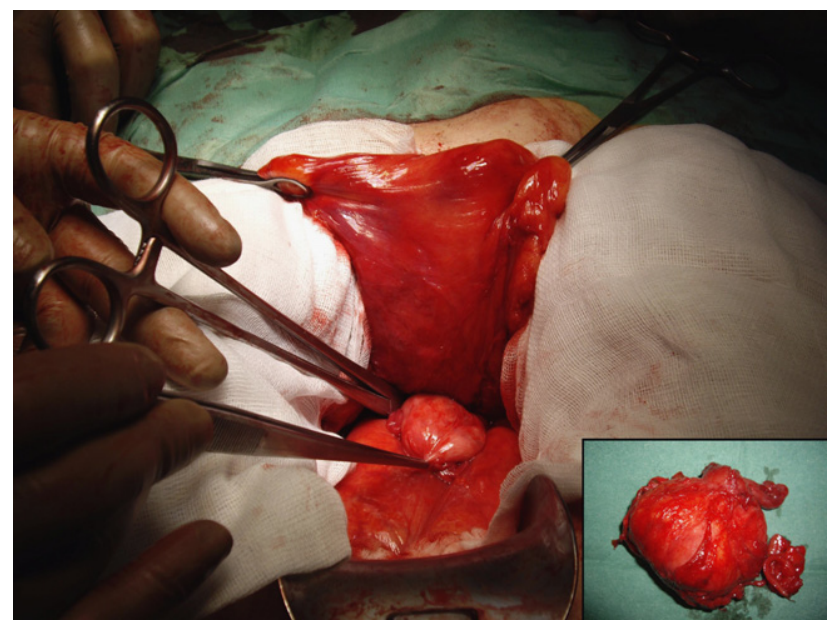

Figura 2 - Cirugía: exposición del tumor con la vejiga desplazada hacía delante (imagen pequeña-pieza quirúrgica). 